\title{
José de Alencar e a floresta do Brasil
}

\section{Eduardo Vieira Martins}

Resumo: Tomando como ponto de partida a análise das descrições dos rios Paquequer e Paraíba, inseridas, respectivamente, na abertura e no epílogo de O guarani, este ensaio pretende discutir a técnica descritiva de José de Alencar. Palavras-chave: natureza, romantismo, descrição.

Abstract: Beginning with the analysis of the descriptions of the rivers Paquequer and Paraiba, wich are inserted in $\mathrm{O}$ guarani's inauguration and epilogue, this paper aims to investigate José de Alencar's description technique. Keywords: nature, Romanticism, description. 


\section{Cor local e nacionalismo}

No primeiro capítulo de O guarani (1857), intitulado “Cenário", o narrador nos leva até a Serra dos Órgãos e, com grande minúcia descritiva, nos apresenta o rio Paquequer, a floresta circundante e a casa de d. Antonio de Mariz, palco dos principais acontecimentos narrados. Além dessa longa apresentação, o romance traz, entremeadas à ação, diversas descrições da natureza, algumas delas contando com vários parágrafos, como, por exemplo, a descrição do pôr do sol, no começo do sétimo capítulo da primeira parte, ou a descrição da tempestade e da cheia do rio Paraíba, no "Epílogo". Essa atenção ao espaço pode parecer excessiva ao leitor de hoje, impaciente para entrar no fluxo da história e seguir o fio dos acontecimentos até o final. Contudo, a descrição constitui um aspecto importante do romance romântico e merece consideração especial. Ao analisar o aparecimento da ficção na literatura brasileira, Antonio Candido observa que "o romance romântico [...] elaborou a realidade graças ao ponto de vista, à posição intelectual e afetiva que norteou todo o nosso romantismo, a saber, o nacionalismo literário". " Essa orientação nacionalista favoreceu o desejo de fixar a cor local, multiplicando ao infinito o que na época se chamava de "quadros" ou "cenas da natureza", longos painéis descritivos nos quais a paisagem era fixada nos seus mais diversos aspectos.

Dessa maneira, a descrição, até então concebida como um dos muitos ornamentos de que dispunham oradores e poetas, passou a receber um lugar especial na poética oitocentista, atraindo a atenção de escritores e críticos. O próprio José de Alencar, antes mesmo de começar a produzir romances, já refletia sobre a questão em diversas passagens das Cartas sobre "A confederação dos Tamoios", publicadas em 1856. Para o crítico, o principal defeito do poema de Magalhães era a falta ao decoro, compreendido como adequação às regras do gênero e à grandiosidade do tema cantado. Dentre os diversos aspectos do poema em que o defeito se manifestava, o folhetinista destacou as descrições da natureza, que considerava inferiores não apenas ao objeto do canto mas também às realizadas por escritores como Chateaubriand e Bernardin de Saint-Pierre. Para Alencar, comparados à prosa musical de Voyage en Amérique, os versos de Magalhães soavam "ocos e sem sentido"; nas suas páginas descritivas, dizia ele, "apenas se encontram esses lugares comuns, essas ideias vulgares que assaltam o espírito, logo que se fala de uma

CANDIDO, Antonio. Formação da literatura brasileira. Belo Horizonte: Itatiaia, 1981, v. 2, p. 112. 
mata ou de um bosque". ${ }^{2}$ No início da primeira carta, afirma que, se fosse poeta e quisesse pintar a natureza de seu país, procuraria esquecer-se de suas ideias de "homem civilizado" e só então entraria nas florestas para colher suas impressões, livre de qualquer anteparo que pudesse turvar seu olhar:

Filho da natureza embrenhar-me-ia por essas matas seculares; contemplaria as maravilhas de Deus, veria o sol erguer-se no seu mar de ouro, a lua deslizar-se no azul do céu; ouviria o murmúrio das ondas e o eco profundo e solene das florestas.

E se tudo isto não me inspirasse uma poesia nova, se não desse ao meu pensamento outros voos que não esses adejos de uma musa clássica ou romântica quebraria a minha pena com desespero, mas não a mancharia numa poesia menos digna de meu belo país. ${ }^{3}$

No plano programático, os quadros da natureza seriam a expressão incondicionada do impacto recebido pelo poeta diante da magnificência da floresta tropical. $\mathrm{Na}$ prática, entretanto, podem-se perceber nessas páginas descritivas marcas tanto do diálogo com modelos literários, quanto do debate teórico travado no período. Assim, se o romantismo rompeu com a convenção descritiva do século XVIII, recusando a tópica do locus amoenus, que lhe parecia falsear a realidade da natureza americana, não foi para pintar uma natureza livre de mediações culturais, como propunham os manifestos, mas para criar uma nova convenção literária, tão formalizada e passível de codificação quanto a anterior. Neste artigo, gostaria de reler as descrições do cenário pintadas por Alencar na abertura e no epílogo de O guarani, procurando ressaltar alguns dos pressupostos que parecem ter orientado a sua produção e que eram compartilhados pelos escritores do período, empenhados no trabalho de nacionalizar a literatura por meio da fixação da cor local.

2 ALENCAR, José de. Cartas sobre "A confederação dos Tamoios". In: CASTELLO, José Aderaldo. A polêmica sobre "A confederação dos Tamoios". São Paulo: Faculdade de Filosofia, Letras e Ciências Humanas/Universidade de São Paulo, 1953, p. 53. 


\section{Imagens fluviais}

$\mathrm{Na}$ abertura de $\mathrm{O}$ guarani, o olhar do narrador, situando-se de uma perspectiva elevada, descreve o rio Paquequer e circunscreve o espaço por onde ele corre:

De um dos cabeços da Serra dos Órgãos desliza um fio de água que se dirige para o norte, e engrossado com os mananciais que recebe no seu curso de dez léguas, torna-se rio caudal.

É o Paquequer: saltando de cascata em cascata, enroscando-se como uma serpente, vai depois se espreguiçar na várzea e embeber no Paraíba, que rola majestosamente em seu vasto leito. ${ }^{4}$

Um dos elementos que chama a atenção nessa abertura e foi repetidamente destacado pela crítica (Augusto Meyer, ${ }^{5}$ Silviano Santiago, ${ }^{6}$ Valéria De Marco) é a cerrada ornamentação empregada na descrição do rio. A princípio, seu movimento é apresentado por uma série de catacreses, ou seja, termos figurados motivados pela falta de nomes próprios: "fio de água"; "se dirige"; "saltando"; "se espreguiçar", "embeber" - expressões metafóricas de tal maneira absorvidas pela língua que nem nos damos conta do seu aspecto transladado. ${ }^{7}$ No segundo parágrafo, uma comparação desenha o rio "enroscando-se como uma serpente" e, a partir do terceiro parágrafo, uma sequência de quatro comparações vai apresentá-lo: 1) como um "vassalo" que "curva-se humildemente aos pés do suserano"; 2) "como o filho indômito desta pátria da liberdade"; 3) "como o tapir, espumando, deixando o pelo esparso pelas pontas do rochedo, e enchendo a solidão com o estampido da sua carreira"; e, finalmente, 4) "como o tigre [que se precipita de um só arremesso] sobre a presa" (p. 51). Terminada a descrição do rio, o narrador apresenta a floresta, descrita em rápidos traços, por meio de metáforas arquitetônicas que a aproximam de um templo ou de um palácio:

4 ALENCAR, José de. O guarani. São Paulo: Ateliê, 1999, p. 51.

5 MEYER, Augusto. "Alencar e a tenuidade brasileira". In: ALENCAR, José de. Obra completa. Rio de Janeiro: Aguilar, 1964.

6 SANTIAGO, Silviano. Liderança e hierarquia em Alencar. In: Vale quanto pesa. Rio de Janeiro: Paz e Terra, 1982.

7 Para Francisco Freire de Carvalho, a catacrese é uma metáfora produzida "por necessidade, isto é, por faltar na língua palavra própria para significar uma determinada ideia". Ver CARVALHO, Francisco Freire de. Lições elementares de eloquência nacional. Lisboa: Rolland \& Semiond, 1880, p. 119-20.

458 MARTINS, Eduardo Vieira. José de Alencar e a floresta do Brasil 
"A vegetação nessas paragens ostentava outrora todo o seu luxo e vigor; florestas virgens se estendiam ao longo das margens do rio, que corria no meio das arcarias de verdura e dos capitéis formados pelos leques das palmeiras".

O narrador inicia a descrição do Paquequer utilizando uma série de metáforas já absorvidas pela linguagem cotidiana, contudo, assim que os elementos aproximados saem do campo da percepção imediata, abandona a metáfora e adota a comparação, mais facilmente apreendida pelo leitor, o que evidencia uma preocupação com a clareza. Metáfora e comparação são ornamentos que trabalham com relações de semelhança. De forma simplificada, pode-se dizer que, no caso da metáfora, a percepção de um elemento comum a dois objetos distintos permite ao orador usar o nome de um para designar o outro. Já na comparação, depois de identificar o elemento comum, o orador coloca os dois objetos lado a lado, explicitando a operação por meio de uma partícula comparativa. Nos dois casos, ao colocar uma coisa sob os olhos do leitor, o efeito obtido é visual, os dois procedimentos procuram dar a ver um objeto desconhecido por meio da apresentação de um objeto conhecido. Note-se ainda que o efeito produzido pelas metáforas com verbos que implicam determinação (dirigir-se, saltar) e pelas comparações com seres animados (serpente, tapir, tigre) é a zoomorfização do rio.

A escolha da metáfora e da comparação como ornamentos privilegiados para a descrição da natureza em O guarani não é casual, ela parece ter sido motivada pela concepção de língua primitiva que se tinha no período. O pastor e professor escocês Hugh Blair, apologista dos poemas ossiânicos de Macpherson e autor das Lectures on rhetoric and belles lettres (1783), livro difundido no Brasil do século xIX por meio de traduções francesas, afirmava que a carência lexical obrigava os homens primitivos a usar o nome de uma coisa para designar outra, conferindo à sua linguagem um caráter fortemente figurado. ${ }^{9}$ Nas Lições de eloquência nacional (1846), o padre Lopes Gama traduziu um fragmento em que Blair discutia a questão:

Nunca as línguas encerram maior número d’expressões figuradas, do que nos primeiros tempos da sua formação; porque então são elas mui pobres; a série das palavras aplicadas às cousas é pouco numerosa, e ao mesmo tempo a imaginação exerce grande influência sobre as concepções do homem, e sobre os seus meios d'expressão, de sorte que já por necessidade, já por escolha os tropos de contínuo se multiplicam. Todos os objetos novos espantam, 
surpreendem, ou produzem sobre o espírito uma impressão mui viva: os homens são muito mais sujeitos ao império das paixões, do que ao da razão, e a sua linguagem se colora com os matizes do seu caráter. A experiência nos mostra que tal era efetivamente a índole das Línguas, que falavam os Índios, e os Americanos, isto é; atrevido, pinturesco, e metafórico, cheio de alusões vivas a qualidades, que caem debaixo dos sentidos, ou aos objetos, com os quais esses povos em sua vida solitária se achavam muitas vezes em relação. Quando qualquer chefe Indiano dirigia a palavra à sua tribo, prodigalizava metáforas mais atrevidas, do que se encontram em nenhum dos Poemas Épicos publicados na Europa. ${ }^{10}$

É essa ideia que orienta Alencar na formulação da linguagem dos seus índios, como explicita o narrador de O guarani, a propósito de Peri: "Poeta primitivo, canta a natureza na mesma linguagem da natureza; ignorante do que se passa nele, vai procurar nas imagens que tem diante dos olhos a expressão do sentimento vago e confuso que lhe agita a alma". ${ }^{11}$ Num movimento mimético, o narrador incorpora ao seu próprio discurso as figuras que o seu tempo e cultura atribuíam à linguagem indígena. Concebendo a língua primitiva como caracterizada por uma carência que lhe impunha a necessidade de recorrer à natureza sensível para figurar ideias abstratas, o romancista descreve a natureza por meio de um procedimento semelhante, reduplicando suas imagens, como já observou Cavalcanti Proença ${ }^{12}$ num conhecido estudo sobre Iracema: dessa perspectiva, o rio Paquequer torna-se sucessivamente serpente, vassalo, tapir e tigre. Contudo, diferentemente das comparações ou metáforas que se acreditava serem recorrentes nas línguas primitivas, que utilizavam imagens do mundo sensível para transmitir ideias abstratas para as quais não havia nomes, n'O guarani as comparações aproximam o rio, objeto para o qual dispomos de um nome, a seres vivos conhecidos, ainda que alguns mais familiares (a serpente, o tigre) e outros menos comuns (o tapir, uma espécie de anta). Para Francisco Freire de Carvalho, autor de um manual de eloquência bastante difundido no período, "a regra principal que deve observar o orador nas pinturas por Semelhanças é pôr um particular cuidado em que a cousa de que tira a Semelhança não seja escura, nem desconhecida, antes sim familiar aos seus ouvintes, porque aquilo que se traz para

GAMA, Miguel do Sacramento Lopes. Lições de eloquência nacional. T. I. Rio de Janeiro: Paula Brito, 1846, p. 124-5. de Janeiro: José Olympio, 1965. 
aclarar outra cousa deve ser mais claro do que esta a que dá luz [...]”. ${ }^{13}$ É evidente que, na abertura do romance, as sucessivas comparações visam a mostrar, não o que é um rio, mas sim o que o Paquequer tem de específico, o elemento particular que caracteriza o objeto genérico: por um lado, a liberdade e a energia que o rio, longe da foz, tem em comum com os seus comparantes; por outro, mas não menos importante, a docilidade com que se curva ante o seu senhor, o Paraíba.

As comparações com animais, especialmente os dotados de grande vigor e energia, como o tigre e o tapir, têm a finalidade de prover o rio de uma dimensão sublime, explicitada no parágrafo que fecha a descrição da floresta: “Tudo era grande e pomposo no cenário que a natureza, sublime artista, tinha decorado para os dramas majestosos dos elementos, em que o homem é apenas um simples comparsa". ${ }^{14}$ Ainda que indicada na abertura, é apenas no "Epílogo" do romance que o cenário vai mostrar toda a sua sublimidade. O décimo capítulo da última parte de O guarani termina com Peri e Ceci fugindo numa canoa, da qual o índio, devidamente batizado e renomeado, testemunha a destruição do solar de dom Antonio de Mariz. O capítulo décimo primeiro, intitulado "Epílogo", divide-se em cinco partes e cobre um período de três dias, nos quais ocorrerão o reconhecimento do amor de Ceci e a grande enchente do rio Paraíba, responsável por aproximar o casal, que, como no mito de Tamandaré narrado por Peri, repovoará o novo mundo depois que as águas abaixarem. A cena da enchente é cuidadosamente preparada pelo narrador por meio de três descrições da floresta. Na primeira, assistimos a um entardecer no qual o índio já reconhece os sinais da tempestade que se aproxima. Nessa passagem, fortemente visual, o narrador mistura os tons amenos do crepúsculo com as cores carregadas que anunciam a catástrofe:

Sobre a linha azulada da cordilheira dos Órgãos, que se destacava num fundo de púrpura e rosicler, amontoavam-se grossas nuvens escuras e pesadas, que, feridas pelos raios do ocaso, lançavam reflexos acobreados.

Daí a pouco, a serrania desapareceu nesse manto cor de bronze [...]. O azul puro e risonho que cobria o resto do firmamento contrastava com a cinta escura, que ia enegrecendo gradualmente à medida que a noite caía. ${ }^{15}$ 
Logo a seguir, a segunda descrição mostra o aspecto da noite, acrescentando, às cores utilizadas no quadro do entardecer, uma sensação tátil que vem reforçar a aproximação da tempestade:

Anoiteceu.

O horizonte, sempre negro e fechado, se iluminava às vezes com um lampejo fosforescente; um tremor surdo parecia correr pelas entranhas da terra e fazia ondular a superfície das águas, como o seio de uma vela enfunada pelo vento.

Entretanto, ao redor tudo estava quieto $[\ldots] .^{16}$

Finalmente, a terceira descrição pinta o quadro da floresta na noite cerrada e, aos sentidos da visão e do tato, empregados nas descrições anteriores, introduz a audição:

Era alta noite; sombras espessas cobriam as margens do Paraíba. De repente um rumor surdo e abafado, como de um tremor subterrâneo, propagando-se por aquela solidão, quebrou o silêncio profundo do ermo.

Peri estremeceu $[\ldots] .^{17}$

A aproximação da tempestade é indicada por uma espécie de crescendo, que solicita um novo sentido a cada descrição: a primeira é puramente visual; a segunda é visual e tátil ("tremor", "ondular"); a terceira é visual, tátil e auditiva ("rumor"). Quando o som finalmente é ouvido, Peri estremece na canoa: homem da natureza, o índio repercute a ondulação que percorre as águas. A partir desse momento, acompanhando o olhar do herói, o narrador passa a descrever o rio Paraíba, retomando o estilo fortemente ornamental que havia sido utilizado na abertura do romance, mas, agora, destacando os elementos sublimes do cenário, em particular a força da tempestade e o terror incutido por ela. A atração do romantismo pelos elementos ameaçadores da natureza pode ser relacionada à teoria desenvolvida por Edmund Burke em A philosophical enquiry into the origin of our ideas of sublime and beautiful (1757), cujas ideias foram divulgadas no Brasil pelas Lectures on rhetoric and belles lettres, de Hugh Blair,

16 Idem, p. 497.

17 Idem, p. 497-8. 
e por seus seguidores oitocentistas, como o português Francisco Freire de Carvalho. Nesses tratados, a tentativa de discriminar as fontes do sublime na natureza levou à constituição de uma espécie de tópica que seria retomada por escritores e pintores do período. Francisco Freire de Carvalho, por exemplo, ao fazer uma tradução resumida das Lectures de Blair, aponta dez fontes do sublime na natureza, entre elas as vastas amplidões, os sons estrepitosos, o pavor, a obscuridade e a força. ${ }^{18}$ Sempre seguindo o professor escocês, Freire de Carvalho considerava a força, e não o terror, como o elemento comum a todos os objetos sublimes: daí advém o interesse pelos aspectos convulsos da natureza, como os vulcões, os incêndios e, o que nos interessa mais diretamente aqui, as inundações:

Um rio correndo ao longo das suas margens é um objeto belo; porém se ele sai do seu álveo, transbordando com estrépito e impetuosidade, ei-lo convertido imediatamente num objeto sublime: Sendo para notar que é dos leões, e de outros animais famosos por sua força, que os bons poetas extraem comparações sublimes [...].

Convém igualmente observar-se que todos os objetos graves e majestosos, ou que imprimem pavor, contribuem poderosamente para fazerem nascer o Sublime, tais são as trevas, a solidão, e o silêncio. Quais são as cenas, que levam a alma ao mais subido grau de elevação, e que produzem o Sublime? De certo não são as risonhas paisagens, os campos cobertos de flores, as cidades opulentas; antes sim as montanhas cobertas de neve, um lago solitário, uma antiga floresta, uma torrente que se despenha por entre rochedos. Daqui vem por igual razão, que as cenas noturnas são ordinariamente as mais sublimes [...].19

Em conformidade com essas ideias, Alencar lança mão da tópica do sublime e põe em cena os elementos aptos a criar a ambiência adequada à grandiosidade do desfecho do romance: explosão, incêndio, tempestade, estrondos, inundação (fontes do sublime na natureza); resignação perante a morte, coragem e força sobre-humanas para afrontar

Segundo Francisco Freire de Carvalho, as dez fontes do sublime são o "vasto"; os sons estrepitosos; a "força"; o "pavor"; a "obscuridade"; os objetos "elevados" ou "de nós separados por longos intervalos de tempo ou de lugar"; a "desordem"; as grandes dimensões de um objeto produzido pelo esforço humano; o heroísmo e a magnanimidade, fontes do sublime moral; e, finalmente, a "virtude remontada, e a coragem fora do comum", mesmo quando voltadas para ações moralmente condenáveis. Cf. CARVALHO, Francisco Freire de. Lições elementares de poética nacional, seguidas de um breve ensaio sobre a crítica literária. Lisboa: Tipografia Rollandiana, 1840, p. 34-47.

19 Idem, p. 36-7.

Teresa revista de Literatura Brasileira [12|13]; São Paulo, p. 455-468, 2013 • 463 
as fúrias dos homens e da natureza (fontes do sublime moral). Na descrição do rio Paraíba, o narrador retoma a comparação do Paquequer com uma serpente, já utilizada na abertura do romance, e a emprega novamente, mas, agora, acentuando o aspecto terrível da imagem: "[Peri] estendeu os olhos pela larga esteira do rio, que, enroscando-se como uma serpente monstruosa de escamas prateadas, ia perder-se no fundo negro da floresta". ${ }^{\circ} \mathrm{O}$ efeito de sublime nessa descrição é produzido não apenas pelo adjetivo "monstruosa", mas também pelo jogo de claro-escuro, sugerido pelo contraste do negrume da floresta com as "escamas prateadas" do rio-serpente, que, dessa maneira, assemelha-se a um raio iluminando o céu. Outros elementos tomados da tópica do sublime são a noite, as "sombras espessas", a "solidão" e o "silêncio profundo do ermo", ${ }^{21}$ que contribuem para aumentar o terror provocado pela tempestade. Por fim, as comparações hiperbólicas com animais, monstros e gigantes terminam por conferir ao quadro a grandeza conveniente: "o Paraíba, levantando-se qual novo Briareu no meio do deserto, estendia os cem braços titânicos e apertava ao peito, estrangulando-a em uma convulsão horrível, toda essa floresta secular que nascera com o mundo". ${ }^{22}$

\section{A técnica descritiva}

As imagens utilizadas por Alencar na descrição dos rios e da floresta não são inovadoras, antes compunham o arsenal de poetas e romancistas seus contemporâneos, e, no caso do sublime, encontravam-se codificadas nos manuais de poética e retórica do período. O paralelo entre a floresta e um templo religioso, a projeção de uma ordem política sobre o mundo natural e a comparação entre fenômenos da natureza e animais selvagens eram frequentes. N'A confederação dos Tamoios, poema ao qual O guarani pode ser lido como uma espécie de resposta, Gonçalves de Magalhães descrevia o Amazonas como "gigante caudaloso", "outro Briareu" e, até mesmo, como "rei dos rios", ao qual "Mil feudatários rios vêm pagar-lhe/ Tributo perenal de suas águas". ${ }^{23}$ Contudo, se comparada à descrição do Amazonas, a do Paquequer parece muito mais moderna, não apenas em decorrência do gênero em que cada uma delas se insere, mas também pelas metáforas de sabor arcaizante ("argênteo salso", por exemplo) e pelas inúmeras inversões sintáti-

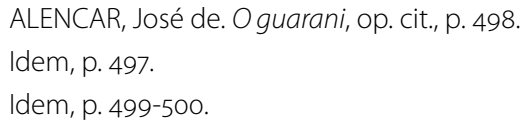


cas ${ }^{24}$ que aproximam o poema de Magalhães às traduções realizadas por Manuel de Odorico Mendes na mesma época. Se compararmos a descrição do Paquequer com a do Meschacebé, traçada na abertura de Atala, a diferença também é evidente. Ainda que aponte Chateaubriand como seu modelo, ${ }^{25}$ não há em Atala o acúmulo de ornamentos presente n'O guarani, o que pode sugerir um desejo de emulação de Alencar com relação ao mestre francês. Assim, ainda que não fossem novas, a habilidade com que Alencar maneja as imagens assegura a eficácia dos quadros da natureza inseridos na narrativa e convida a pensar sobre a técnica descritiva empregada pelo romancista.

Tanto em Alencar quanto em outros escritores do período, incluindo viajantes naturalistas, percebe-se uma preocupação em organizar a descrição da floresta de maneira a apreender tanto o efeito produzido pela contemplação do todo quanto a riqueza dos detalhes presentes em cada uma de suas partes. Esse jogo entre a parte e o todo implicava uma oscilação de perspectivas: enquanto a apreensão do conjunto requeria a adoção de um ponto de vista elevado, apto a abarcar vastas porções do território, a fixação das partes dependia de um processo de focalização e deu ensejo às listas de elementos, como nomes de pássaros, animais e plantas. O desejo de representar a floresta de maneira a captar o efeito produzido pelo todo, mas sem perder a multiplicidade dos detalhes, não era exclusivo dos escritores, manifestando-se também na pintura oitocentista. Ao comentar a sépia intitulada A floresta virgem do Brasil, de autoria do conde de Clarac, companheiro de Auguste de Saint-Hilaire na comitiva Luxemburgo, Pedro Corrêa do Lago observa que o pintor "impôs-se o desafio de tentar uma representação da selva brasileira que atendesse aos preceitos de Humboldt, e que fosse ao mesmo tempo fiel ao detalhe e capaz de passar uma impressão de conjunto da extraordinária riqueza e exuberância da natureza tropical". ${ }^{26}$ Clarac tentou equacionar o problema completando o esboço do quadro, realizado no próprio local, com a pintura detalhada de espécies brasileiras observadas numa estufa mantida na Europa, onde ele concluiu o trabalho. ${ }^{27}$ Apesar dos seus esforços, ele não escapou de críticas, como a formulada por Manuel de Araújo Porto-Alegre, para quem, assim como outros quadros pintados por estrangeiros, o de Clarac também deturpava o modelo:

"O das águas gigante caudaloso/ Que pela terra alarga-se vastíssimo/ Do oceano rival, ou rei dos rios [...]". Cf. MAGALHÃES, Gonçalves de. A confederação dos Tamoios, op. cit., p. 13.

25 "Quanto à poesia americana, o modelo para mim ainda hoje é Chateaubriand [...]." Cf. ALENCAR, José de. Como e por que sou romancista. Campinas: Pontes, 1990, p. 60.

26 LAGO, Pedro Corrêa do. Taunay e o Brasil. Rio de Janeiro: Capivara, 2008, p. 54.

27 Idem. 
O toque da folhagem das árvores, das parasitas, das bromélias, das gramíneas ou taquaras, e das plantas aquáticas, não era exato, nem a colocação destas plantas localizada convenientemente; há defeitos na forma geral e característica, há desproporção entre sua grandeza, e infidelidade no tipo geral que especifica as regiões intertropicais. ${ }^{28}$

No tocante à descrição literária, o problema da relação entre as partes e o todo foi discutido por José de Alencar numa nota das Cartas sobre "A confederação dos Tamoios". Ao analisar uma das descrições da floresta presentes no poema, o crítico repreende Magalhães por ter desviado a atenção do conjunto para o detalhe, comprometendo a grandiosidade do painel:

Para sentir quanto o poeta ficou neste ponto aquém da realidade basta ter atravessado ao meio-dia uma dessas florestas seculares, onde tudo é majestoso e grande como a natureza nas suas formas primitivas.

Em vez de pintar-nos a cena, em suas vastas proporções, em vez de traçar um quadro grandioso, o sr. Magalhães preferiu descrever os detalhes, e apresentar os pirilampos a fazerem evoluções desconhecidas na história desses insetos.

Um pintor que desejando pintar uma tempestade em vez da cena majestosa da natureza, se ocupasse em pintar uns barquinhos no mar acossado pelo vento, faria um quadro defeituoso; o mesmo sucede ao poeta que desprezou a harmonia do todo pela minúcia dos detalhes. ${ }^{29}$

Ainda uma vez, como a pintura, a poesia. Em outra passagem das Cartas, Alencar cita um crítico de Homero, segundo o qual "a descrição grega se compõe de poucos traços, e se ocupa mais em fazer sentir a vida de um objeto do que em representá-lo por seu aspecto material [...]".30 Assim, a impressão que se tem é que, para Alencar, a representação do todo não poderia ser poeticamente obtida por meio da enu-

PORTO-ALEGRE, Manuel de Araújo. Breves reflexões que submeto à consideração do sr. Müller, professor da aula de paisagem, flores e animais, acerca do seu programa de ensino apresentado ao Corpo Acadêmico em sessão de 29 de outubro de 1855. Revista do Patrimônio Histórico e Artístico Nacional. Rio de Janeiro: MEC, n. 14, 1959, p. 52. Esse texto me foi indicado pelo Prof. Luciano Migliaccio, a quem gostaria de registrar o meu agradecimento.

29 ALENCAR, José de. Cartas sobre "A confederação dos Tamoios", op. cit., p. 53, n. 13.

30 Idem, p. 48. 
meração exaustiva das partes; ela dependia, antes, da apreensão de um elemento significativo, que pudesse ser investido de dimensão simbólica. Por isso, na abertura d'O guarani, do vasto panorama descortinado a partir "de um dos cabeços da Serra dos Órgãos" (perspectiva elevada), é a descrição do rio e, principalmente, a impressão que ele produz sobre o narrador, sugerindo-lhe uma série de comparações, que ocupam o centro do quadro. Há um deslocamento do foco de atenção, que deixa o objeto descrito para registrar as sensações que esse objeto desperta no narrador, as comparações que ele lhe inspira. Como um selvagem que, sem palavras para expressar o sentimento de exaltação diante das belezas que o circundam, lança mão de tropos provocados pela necessidade, a vertiginosa sequência de imagens projetada sobre o Paquequer ou sobre o Paraíba deveria sugerir, não apenas a grandeza e a força dos rios, mas o sentimento de sublime arrebatamento que a sua contemplação provoca no observador. O quadro da natureza transcende a dimensão descritiva para se converter numa espécie de panegírico por meio do qual o narrador manifesta sua admiração diante do cenário e procura suscitar a mesma paixão no leitor.

Além da eficácia com que soube identificar o detalhe representativo para sugerir a grandiosidade do todo, outro elemento que parece contribuir decisivamente para a eficácia das descrições alencarianas é a maneira com que elas são articuladas à narrativa. ${ }^{31}$ Ao contrário das descrições técnicas dos relatos de viajantes naturalistas, que visavam primordialmente a fornecer informações precisas, a descrição do romancista atende a finalidades muito diversas. Tradicionalmente, a teoria e a crítica literárias analisam as descrições como índice de caráter dos personagens ou como ornamento do discurso. Sob o primeiro aspecto, Gerard Genette observa que a descrição "é de ordem simultaneamente explicativa e simbólica"; ela tende "a revelar e ao mesmo tempo a justificar a psicologia dos personagens, dos quais são ao mesmo tempo signo, causa e efeito" ${ }^{32} \mathrm{O}$ uso do cenário como índice do caráter das personagens é magistralmente utilizado por Alencar em seus romances. $\mathrm{Na}$ abertura d'O guarani, além da indicação do caráter de dom Antonio de Mariz por meio de elementos da sua casa, há um esforço evidente em estabelecer uma proporção segundo a qual Peri está

Valéria De Marco já chamou a atenção para esse aspecto: "a vitalidade das imagens d'O guarani não decorre apenas da elaboração dada a elas pela frase mas também do modo de inserção dessas imagens no romance, do modo como outros pilares do texto as sustentam". Ver MARCO, Valéria de. A perda das ilusões. Campinas: Unicamp, 1993, p. 27. 
para o Paquequer da mesma maneira que dom Antonio está para o Paraíba: assim como o Paquequer, Peri, vassalo, curva-se diante de dom Antonio de Mariz, seu suserano. Assim como o Paquequer, Peri, para ser apreciado em toda a sua grandeza de rei das florestas, não deve ser visto ao lado de dom Antonio (Paraíba), mas "sim três ou quatro léguas acima de sua foz, onde é livre ainda, como o filho indômito desta pátria da liberdade". ${ }^{33}$ Significativamente, é apenas depois da destruição da casa de seu pai, quando se encontra sozinha com o índio, em meio à floresta, onde "todas as distinções desapareciam", ${ }^{44}$ que Ceci pode olhar pela primeira vez para ele e perceber a "beleza inculta dos traços, da correção das linhas do perfil altivo, da expressão de força e inteligência que animava aquele busto selvagem moldado pela natureza". ${ }^{35}$ A par dessa utilização como índice de caráter ou de atmosfera, as descrições da natureza também possuem função ornamental, aspecto que foi largamente discutido por Alencar nas Cartas sobre "A confederação dos Tamoios". Nos comentários sobre os quadros da natureza presentes no poema, o que o folhetinista censura não é sua falta de fidelidade ao real, mas, sim, sua falta de poesia:

Até aqui, ainda não encontrei uma dessas descrições a que os poetas chamam quadros ou painéis, e nas quais a verdadeira, a sublime poesia revela toda a sua beleza estética, e rouba para assim dizer, à pintura as suas cores e os seus traços, à música as suas harmonias e os seus tons. ${ }^{36}$

É justamente essa falta de poesia que o romancista procura sanar com a rica ornamentação que vimos aplicada aos rios Paquequer e Paraíba. A habilidade com que pintou esses quadros fez deles uma das mais poderosas e duradoras imagens formuladas pelo século xıx para a jovem nação fundada em 1822 .

Eduardo Vieira Martins é professor do Departamento de Teoria Literária e Literatura Comparada da FFLCH-USP e autor de A fonte subterrânea. José de Alencar e a retórica oitocentista (Edusp/Eduel, 2005).

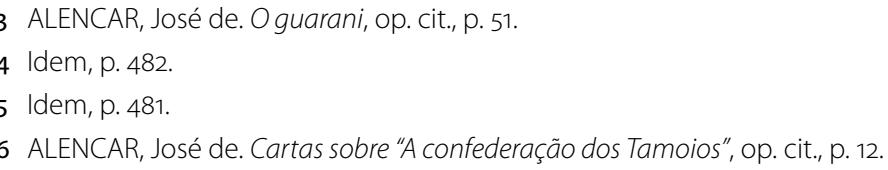

